IMAGES IN PAEDIATRICS

\section{Interesting case of traumatic paediatric chest pain: don't forget the vessels}

A male adolescent was a restrained passenger in a high-speed road traffic collision. At the scene he was noted to be hypotensive and received one unit of blood. In the emergency department, he presented with mild chest pain. He had a normal chest examination. A $20 \mathrm{~mm} \mathrm{Hg}$ blood pressure difference was found between his right and left arms. His CT chest is displayed in figure 1.

\section{QUESTIONS}

1. What is the most likely cause of the CT appearance identified by arrow 'C'?
A. Pneumothorax
B. Haemothorax
C. Empyema
D. Pulmonary contusion

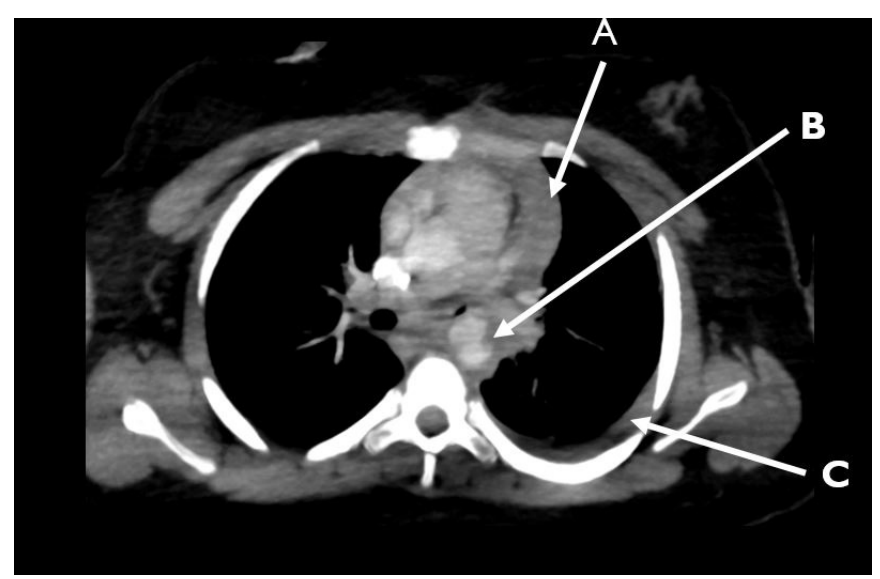

Figure $1 \mathrm{CT}$ chest with contrast, axial $3 \mathrm{~mm}$ slice taken just below the level of the subclavian artery origin.
2. What does the arrow 'B' show?
A. Aortic dissection
B. Aortic transection
C. Normal anatomy
D. Cardiac tamponade

3. How would you manage this patient acutely?

4. When would you decide to organise a CT chest in a trauma patient?

\section{ANSWERS}

\section{Question 1}

(B) Haemothorax. Arrow 'C' demonstrates fluid within the pleural space; in a trauma setting, blood must be suspected. Air (pneumothorax) appears black on a CT and an empyema (purulent collection) is not in keeping with the clinical case. In trauma, haemothorax occurs from injury to the lungs, heart, chest wall or great vessels.

\section{Question 2}

(B) Aortic transection. Arrow 'B' demonstrates mural irregularity of the aorta with a pseudoaneurysm anteriorly, implying complete disruption of the vessel wall-an aortic transection. This location, the aortic isthmus, is the most common site for this injury.

Additional findings labelled as arrow 'A' show a mediastinal haematoma.

In aortic dissection there is an intimal tear allowing blood to pool between vessel layers (figure 2). ${ }^{12}$ On CT, dissection is evident as an intimal flap leading to a blood-filled space with a true and false lumen. ${ }^{3}$

A high index of clinical suspicion is required to diagnose aortic injury and should be considered in rapid deceleration mechanisms, patients with signs of a chest injury and/or haemodynamic instability.

\section{Question 3}

Follow the 'C-ABC' approach to trauma with administration of tranexamic acid, volume resuscitation with blood products and activation of the major haemorrhage protocol as required. Avoid hypertension which may exacerbate the aortic injury. ${ }^{5}$

Definitive treatment requires mutli disciplinary team input from general paediatric surgeons, cardiothoracic surgeons, vascular surgeons and interventional radiology. Minor aortic injuries may be managed conservatively with follow-up imaging but more significant 

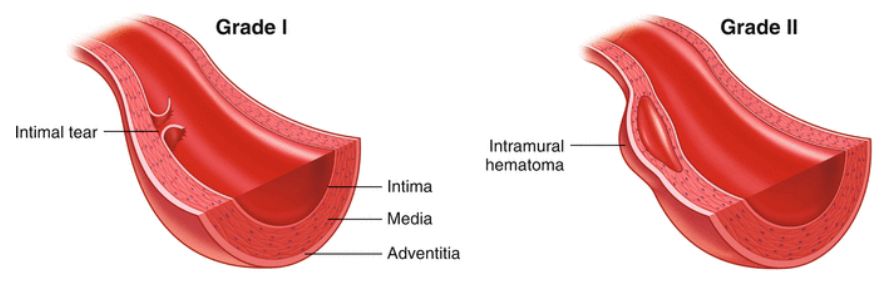

Grade III
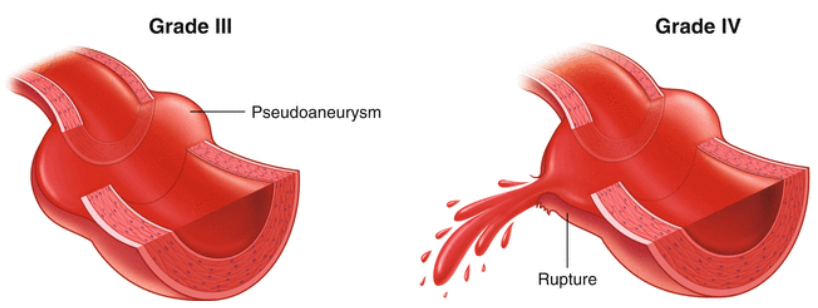

Figure 2 Classification system for traumatic aortic injury. Reproduced from Azizzadeh et al' with permission from Elsevier.

vessel injury requires repair (open vs endovascular). ${ }^{6}$ In this case, the patient was managed with an open repair by cardiothoracics and made a full recovery.

\section{Question 4}

Imaging in the paediatric population is guided by the as low as reasonably achievable principle, aiming to limit unnecessary radiation exposure. Reassuringly, there is no difference in mortality outcomes when targeted imaging is compared with the 'pan-scan'

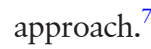

The Royal College of Radiology published recommendations specific to paediatric trauma. ${ }^{8}$ In thoracic injury, chest X-rays should be performed initially to look for mediastinal enlargement, rib fractures, haemothorax/pneumothorax and diaphragmatic injury. If the patient is stable, with no signs of chest trauma and a normal X-ray, no further imaging is recommended. Conversely, in the patients with chest signs (abnormal examination or observations), abnormal chest X-ray and who are unstable without obvious cause, further imaging of the chest should be considered. Contrast-enhanced CT is the modality of choice.

\section{Matthew G W Macartney $\odot$,, Nick Clarke, ${ }^{2}$ Julie-Ann Collins, ${ }^{1}$ Stephen Mullen ${ }^{1}$}

${ }^{1}$ Paediatric Emergency Medicine, Royal Belfast Hospital for Sick Children, Belfast, UK ${ }^{2}$ Radiology, Royal Belfast Hospital for Sick Children, Belfast, UK

Correspondence to Dr Matthew G W Macartney, Royal Belfast Hospital for Sick Children, Belfast BT12 6BA, UK; mmacartney03@qub.ac.uk
Contributors MGWM, JAC and SM collectively managed the case and discussed the idea of sharing their learning. SM provided the manuscript framework and supervised throughout the process. NC provided the CT images.

Funding The authors have not declared a specific grant for this research from any funding agency in the public, commercial or not-for-profit sectors.

Competing interests None declared.

Patient consent for publication Not required.

Provenance and peer review Not commissioned; externally peer reviewed.

\section{(2) OPEN ACCESS}

Open access This is an open access article distributed in accordance with the Creative Commons Attribution Non Commercial (CC BY-NC 4.0) license, which permits others to distribute, remix, adapt, build upon this work non-commercially, and license their derivative works on different terms, provided the original work is properly cited, appropriate credit is given, any changes made indicated, and the use is non-commercial. See: http://creativecommons.org/licenses/by-nc/4.0/.

(C) Author(s) (or their employer(s)) 2022. Re-use permitted under CC BY-NC. No commercial re-use. See rights and permissions. Published by BMJ.

\section{(A) Check for updates}

To cite Macartney MGW, Clarke N, Collins J-A, et al. Arch Dis Child 2022;107:39-40.

Accepted 18 April 2021

Published Online First 30 April 2021

Arch Dis Child 2022;107:39-40. doi:10.1136/archdischild-2021-321621

\section{ORCID iD}

Matthew G W Macartney http://orcid.org/0000-0001-8710-8353

\section{REFERENCES}

1 Azizzadeh A, Keyhani K, Miller CC, et al. Blunt traumatic aortic injury: initial experience with endovascular repair. J Vasc Surg 2009;49:1403-8.

2 McMahon MA, Squirrell CA. Multidetector CT of aortic dissection: a pictorial review. Radiographics 2010;30:445-60.

3 Duran ES, Ahmad F, Elshikh M, et al. Computed tomography imaging findings of acute aortic pathologies. Cureus 2019;11:e5534-e.

4 Karmy-Jones R, Hoffer E, Meissner M, et al. Management of traumatic rupture of the thoracic aorta in pediatric patients. Ann Thorac Surg 2003;75:1513-7.

5 Bansal V, Lee J, Coimbra R. Current diagnosis and management of blunt traumatic rupture of the thoracic aorta. J Vasc Bras 2007;6:64-73.

6 Chiba K, Abe H, Kitanaka Y, et al. Conventional surgical repair of traumatic rupture of the thoracic aorta. Gen Thorac Cardiovasc Surg 2014;62:713-9.

7 Meltzer JA, Stone ME, Reddy SH, et al. Association of whole-body computed tomography with mortality risk in children with blunt trauma. JAMA Pediatr 2018;172:542-9.

8 The Royal College of Radiologists. Paediatric trauma protocols. London: The Royal College of Radiologists, 2014. 